\title{
On the Applicability of Cultural Scripts in Teaching L2 Compliments
}

\author{
Amin Karimnia (Corresponding author). \\ Islamic Azad University, Khorasgan Branch, Iran \\ E-mail: aminkarimnia@yahoo.com \\ Akbar Afghari \\ Sheikhbahaee University, Isfahan, Iran \\ E-mail: afghary@yahoo.com
}

\begin{abstract}
In this study, Natural Semantic Metalanguage (henceforth NSM) was used to carry out a comparative analysis. The compliment response behavior of native Persian speakers was compared with that of Native American English speakers to see if it can provide evidence for applicability of NSM model which is claimed to be universal. The descriptive technique was the cultural scripts approach, using conceptual primes proposed in the NSM theory. The cultural scripts were presented in both English and Persian Metalanguages. The data were taken from a corpus of 50 hours of recording the live interviews from the Persian and English TV channels. The results showed the applicability of NSM model for cross-cultural comparisons. Then, the paper concludes with the pedagogical implications of the development of the theory of cultural scripts for teaching L2 socio- pragmatics in general and compliments in particular.
\end{abstract}

Keywords: NSM, Socio-Pragmatics, Persian, Cultural Scripts, English

\section{Introduction}

Wierzbicka and her colleagues have developed an approach for exploring the cultural underpinning of speech acts which is known as Natural Semantic Metalanguage (e.g., Wierzbicka, 1991; Goddard and Wierzbicka, 2004; Wierzbicka, 2007). Within this approach, cultural values and attitudes, or what they term 'cultural scripts', which give rise to pragmatic devices, are explicated in terms of a set of fundamental meanings, termed semantic primes, which are alleged to be universal.

The cultural scripts technique relies crucially on the metalanguage of empirically established semantic primes. Semantic primes are simple, indefinable meanings which appear to "surface" as the meanings of words or word-like expressions in all languages. The semantic primes and their principles of combination constitute a kind of "mini-language" with the same expressive power as a full natural language. There are about 60 in them, listed by Goddard and Wierzbicka (2004).

According to Wierzbicka (2007, p. 18), the key claim is that the semantic primes expressed by English words like someone/person, something/thing, people, say, words, true, do, think want, good, bad, if, because, among others, can be expressed equally well and equally precisely in other languages; and that, furthermore, they have an inherent universal grammar of combination and complementation which also manifests itself equally in all languages, albeit with language-specific formal variations. The universal mini-language of semantic primes can therefore be safely used as a common code for writing explications of "terminological ethnocentrism" with maximum clarity and resolution of detail, and in the knowledge that they can be readily transposed across languages. It offers a mechanism by which meaning can be freed from the grip of any single language. As the anthropologist Roy D'Andrade (2001) remarks, the natural semantic metalanguage "offers a potential means to ground all complex concepts in ordinary language and translate concepts from one language to another without loss or distortion in meaning"' (p. 246).

Although the primes are being expressed in English, NSM researchers believe that all or most of them will turn out to be semantic fundamentals in all languages. A growing body of research, begun in Goddard and Wierzbicka (1994) and continued in Goddard and Wierzbicka (2004), and other publications suggests that this might be the case. Goddard and Wierzbicka (2004) and Wierzbicka (2007) assert that NSM studies have been carried out in a wide range of languages, including English, Russian, French, Spanish, Polish, Italian, Malay, Japanese, Chinese, Korean and Maori, among others.

Another important point worthy of close consideration is that the majority of classroom-based studies used models of speech acts not based on naturally occurring data samples as instructional material to teach L2 socio-pragmatic norms. They provided their learners with models of L2 socio-cultural norms which are usually exclusively based 
on native speaker intuition. Native speaker intuition, however, affords somewhat idealized versions of social interaction. Furthermore, like most previous studies on interlanguage pragmatics, the findings of these studies are based upon the examination of elicited data (for example, discourse completion tests). While such data may demonstrate learners' explicit knowledge of the L2 socio-pragmatic norms, they tend not to reflect learners' ability to apply their socio-pragmatic knowledge in naturally occurring conversation (Kasper, 2001).

To date, there are only a few studies that show how language use and speech acts such as compliments can be taught in the classroom, for example, Holmes and Brown (1987) show how compliments can be taught and Taleghani-Nikazm (2002) provides a teaching unit on telephone openings in German. While these studies represent a much needed step towards including the analysis of naturalistic conversation in second language classrooms, they do not (yet) assess the outcome of such instruction. In other words, while some studies (Taleghani- Nikazm, 2002) show that students seem to notice and correctly apply the pragmatic rules of the second language, the studies do not evaluate the long-term learning effects of this instruction.

In the present paper, the compliment response behavior of native Persian speakers will be compared with that of Native American English speakers. This paper aims at investigating evidence for or against Wierzbicka's universal theory and its application in the area of teaching L2 compliments.

\section{Methodology}

Different tools and methods of data collection have been used in the study of compliments. They include: (a) discourse completion tasks and questionnaires (e.g., Barnlund and Akari, 1985; Sharifian, 2005; Tang and Zhang, 2009), (b) recall protocols (e.g., Knapp et al., 1984), (c) role play (e.g., Saito and Beecken, 1997), (d) field observation (e.g., Wolfson and Manes, 1980; Herbert and Straight, 1989, and several others) and (e) conversation and discourse analysis (Pomerantz, 1978; Wieland, 1995; Golato, 2002). Golato (2003) discussed the merits and demerits of each of these methods of data collection, noting that each of them allows the researcher to investigate different facets of the topic at hand. Furthermore, she argued that conversation analysis (CA) is well suited for the close study of culturally determined speech events since it makes use of video- and/or audio taped samples of non-elicited face-to-face or telephone conversations, thus allowing for the repeated and detailed analysis of a phenomenon in its sequential context. As a result, both interactional features and nonverbal elements can be included in the analysis. Since the data are always spontaneous, they represent what speakers are actually doing in conversation. Crucially, they do not represent speakers' intuitions, which are not always reliable in such contexts (Golato, 2003). Following the recommendation by Golato (2003), the researchers used naturally occurring interview data which was recorded.

\section{The Corpus}

The data were taken from a corpus of 50 hours of recording the live interviews from the following Persian and English TV channels: VOA Persian TV, IRIB1PER, IRIB2PER, IRIB3PER, IRIB4PER (Persian), CNN, Hope Channel, Inspiration and VOATV1(English). They were randomly selected from a larger pool of English and Persian TV channels and were collected in two months during January and February, 2009. The speakers ranged in age from almost 20 to 75 years. All speakers held or were pursuing a university degree or held white-collar positions (e.g., TV interviewers, politicians, managers, artists, authors, etc.).The 32 speakers (interviewers and interviewees) produced 65 compliment sequences from which 29 were English and 36 were Persian compliment sequences.

\section{The Study}

Wierzbicka (1991) talks about a classification of compliment response routine patterns based on Pomerantz (1978). The present study is also patterned after Pomerantz's (1978) analysis of compliment responses and addresses similarities and differences in the complimenting behavior of English and Persian. These patterns are upgrades, downgrades, contrastive opposites, returns, scaled-down agreements and reassignments of praise.

Throughout the present study, the transcriptions from Persian, the letter "a" symbolizes a low front vowel which is close to the sound of "a" in the word "cat". The "aa" sequence, on the other hand, stands for a low back vowel which is close to the sound of "a" in the word "father".

\subsection{Upgrades and downgrades}

Extract1 (Persian):

A: Tafsireh shomaa chie Aaghaaye Mohammadi shoma ke dar morede masaayele khaavare miaane az ma kheili behtar midunid va dar jaryaan hastid. Note1

[interpretation-of you what Mr. Mohammadi you that in about issues-of Middle East from we 
much know and in informed are you.]

'What is your interpretation, Mr. Mohammadi? You know much better about Middle East issues than we do and are more informed.'

B: Ekhtiaar daarid aaghaaye Hasani, in farmaayeshha ro nafarmaaid. Be har haal...

[The choice rests with you Mr. Hasani, this sayings- obj- marker not say. To each way.....]

'Please Mr. Hasani, do not say so. Any way...'

This is the situation in which the first speaker (interviewer) compliments the other person (interviewee) by raising his position. The other speaker downgrades what the first speaker says by lowering himself. This self-lowering and the other-raising pattern is the commonest strategy in Persian.

The general norm behind this pattern can be portrayed as follows:

I can't say what I feel, think, and want others can't say what they think, feel, and want

The aforementioned norm imposes constraints on one's expression of feeling, thoughts, and wants in Iranian interaction. Therefore, the following interaction routines can be described within the following cultural scripts for Persian:

A: (a) I think your $\mathrm{X}$ is very good

B: (b) I don't think the same

(c) I wouldn't say it is very good because it( $\mathrm{Y})$ is not good

(d) It is not good for you to know what I think or feel

(e) If you know this you could feel something bad towards me

In contrast, the self-lowering and other-raising pattern does not occur in English very often. That is, the interlocutors involved in a compliment interaction do not lower themselves. Their response is usually followed by agreement on the part of the addressee. As in the following example:

Extract2 (English):

A: Thank you, Jack; it was an honor to have you in our program. You are an excellent cook.

B: Oh, yes. I am.

Paying attention to the context from which the above communicative routine was adopted, one can see that the interviewee does not ironically accept the excessive praise bestowed upon him, on the contrary he is serious. This communicative interaction can be described in terms of the following cultural scripts:

A: (a) I think your $\mathrm{X}$ is very good

B: (b) I think the same

(c) I would say $\mathrm{X}$ is very good

The general norm behind the above interaction can be portrayed as follows:

I can say what I feel, think, and want

As far as the first component is concerned, both the English and Persian extracts spell out that some characteristic of the speaker is the target of the compliment. Component (b) in Persian suggests that there is no agreement on the part of the addressee while in English the addressee agrees with what the speaker says. Component (c) in English implies that the addressee reinforces what the speaker says by strengthening it whereas in Persian the addressee lowers himself rejecting it. Component (d) postulates that what the first speaker says can be interpreted differently, that is, Iranian compliment interaction is always characterized by uncertainty. Component (e) shows the consequence of revealing one's true feelings towards the addressee.

Beeman (1986, p. 22) contends that "one important principle of communication in the United States involves a tendency for individuals to try and arrive at a single set of interpretive criteria for understanding the relationship between message form and message content, and this can be glossed as 'certainty'." The above English extract indicates that the addressee reinforces what the speaker says by strengthening it whereas in Persian the addressee lowers himself by rejecting it. Beeman (1986) in this regard asserts: "the impression of uncertainty in Iranian life is based on observation of a core of regular phenomena in interaction and can be stated as a principle of communication: the relationship between message form and message content cannot be interpreted according to any single set of criteria" (p. 24). 


\subsection{Contrastive Opposites}

One of the compliment patterns that frequently occur in Persian is the contrastive opposites as in the following example:

Extract3 (Persian):

A: Bebakhshid, maa emshab kheili ham azyatetun kardim?

[Sorry you, we tonight a lot bother you did]

'Sorry, we bothered you a lot tonight.'

B: Na kheir aslan.

[no no at all.]

'No. not at all.'

A: Maa mojrihaa ye kam ziaadi harf mizanim.

[we interviewers a little much talk we do.]

'We interviewers talk too much.

B: Na. ettefaaghan khosh sohbat hastid.

[no. incidentally pleasant speech are you.]

'No. incidentally you are a pleasant speaker.'

This is the situation in which the interviewer apologizes to the interviewee for what he did (too much talking). In other words, the interviewer blames himself. However, to appear polite, the interviewee denies what the interviewer says implying that he should not blame himself.

The following crucial scripts can be suggested for this interaction routine:

I think $\mathrm{X}$ is very bad because it did something bad to you

I don't think the same

I think your $\mathrm{X}$ is very good

It is not good for you to know what I think, feel or want

If you know this you could feel something bad towards me

Component (a) spells out that the speaker demeans herself by saying that there was really something wrong. Component (b) implies that the addressee does not agree with the speaker denying the fact. Component (c) indicates that the speaker raises the position of the speaker. Component (d) gives us the impression that what the addressee states does not reveal his true feelings. The last component is the corollary of revealing one's true feelings towards both the speaker and the addressee.

Paying attention to the context from which the above communicative routine was adopted, one can see that the interviewer talked too much, that he bothered the interviewee, and that he was entirely intolerable. However, the interviewee, aware of this fact, attempts to give the impression that the interviewer was not such bad company as he thinks he is. In fact, the interviewee is concealing his true feelings towards the problem. If the interviewee expressed his true feelings towards the interviewer, it would be generally considered as impolite. The last two components are in harmony with the following cultural norm in Persian:

I can't say what I think, feel, and want

Others can't say what they think feel, and want

To describe the same pattern in English, an extract from one of the English channels seems to be in order:

Extract 4 (English):

A: I don't know why I can't stop myself. I talk too much.

B: You don't talk too much. You are just lively.

As the short segment suggests, the man speaking demeans himself by confessing the fact that he is too talkative, and that he must try to reform himself maximizing the harshness of his bad behavior. The second speaker opposes to what the first speaker says by raising his position. 
To contrast the English and Persian interaction routines in terms of cultural scripts, it should be noted that the first three components are similar in both English and Persian. Component (a) spells out that the speaker thinks there is something wrong with himself trying to put himself down. Component (b) implies that the addressee opposes what the speaker says. Component (c) postulates that the addressee says something to raise the position of the speaker. The difference basically lies in component (d) and (e). In Persian, the speaker in the complement does not reveal his true feelings while in English, given the social norm, one can express what he feels, thinks, and wants. Besides, in Persian if one says what he truly feels, thinks or wants, someone may feel something bad towards him.

\subsection{Returns}

One of the compliment response routines that occur in both English and Persian is referred to as return. This is basically shown as follows:

A: A compliments B

B: B compliments A

The following extract from English shows how the interlocutors involved return the compliment expression to praise each other:

Extract5 (English):

A: You are a very nice listener, Jane!

B: And you are a nice speaker.

This is the situation in which the speaker talking to a lady speaks highly of her. The addressee returns the compliment, praising him to show a gesture of good feelings. In order to elaborate on this communicative interaction routine, the following cultural scripts have been put forward:

A: (a) I want to say something good about you

(b) I want you to feel something good because of this

B: (c) I want to do the same to you

(d) I want to say something good about you

(e) I want you to feel something good because of this

Component (a) indicates the fact that the speaker wants to say something good about the addressee, the meaning of which is implicit in all compliment interaction routines. Component (b) indicates that what the speaker says is meant to consolidate mutual good feelings towards one another. Component (c) expresses the type of compliment response under consideration here, henceforth, "returns". Components (d) and (e) are, in fact, the reflection of (a) and (b) components described above.

To contrast the same pattern in Persian, the following extract will be in order:

Extract 6 (Persian):

A: Kheili mamnoon aaghaaye doktor. Az mahzare jenaabe aali kheili estefaadeh kardim.

[very much thank Mr. Doctor. From presence you much benefit did we.]

'Thank you very much Mr. Doctor. We benefited from your presence.'

B. Ekhtiaar daarid!

[The choice rests with you (but I disagree)]

'Please!'

This exchange unit can be described with the following cultural scripts:

A: (a) I want to say something good about you

(b) I say your X is good

(c) I want you to feel something good because of this

B: (d) I don't think the same

(e) I want to do the same to you

(f) I want to say something good about you

(g) I want you to feel something good because of this 
(h) It is not good for me to say what I think, feel or want

(I) If you know this you could feel something bad towards me

Components (a) postulates that the speaker is saying something to compliment the addressee, the intent implied from all compliment interaction routines. Component (b) posits that the speaker is making a compliment assertion. Component (c) postulates that what the speaker says is intended to be an expression of good feelings towards the addressee. Component (d) has to do with the fact that the addressee does not agree with the compliment assertion, the meaning implied from the expression 'ekhtiar daarid' uttered by the addressee. Component (e) indicates the type of the compliment used, henceforth, the form. Component (f) and (g) are the reflection of the same components in (a) and (b) in English, hence, the meaning implied. Note that components (h) and (I) do not exist in English. These two components hold that what the speaker and addressee say can be interpreted in terms of what Beeman(1986, p. 22) calls "a hail of uncertainty" over all Iranian communicative interactions. Paying attention to the context from which the Persian exchange unit was taken, one can imply that the interlocutors involved try to conceal their true feelings towards one another.

\subsection{Scaled-down agreement}

This is the pattern in which the addressee agrees with the compliment assertion to some extent. Yet he points to some flaw in the object, rejecting full agreement. For example:

Extract 7 (Persian):

A: Binandegaane aziz in ketaab, ketaabe kheili mofidi hast.

[viewers dear this book, book-of very useful is.]

'Dear viewers, this book is a very useful book.'

B: Albatteh hanuz naghshaee daareh ke dar chaahpe dovvom enshaa 'llah bartaraf mishe.

[of course yet deficiencies has that in edition second hopefully revise will be.]

'Of course, it has some deficiencies that hopefully will be revised in the second edition.'

The exchange unit shows that the speaker is talking highly of the addressee's book. The addressee does not reject the assertion fully, drawing attention to some flaw in the object.

This interactional routine can be described within the following cultural scripts:

A: (a) I think something about you is good

B: (b) I think the same

(c) I think it is good I don't want to say: very good

(d) It is not good for me to say what I feel or think

(e) If you know this you could feel something bad towards me

Component (a) in Persian indicates that the speaker is asserting praise to the addressee, the meaning implicit in all compliment routines. Component (b) shows that the addressee agrees on what is being said. Component (c) posits the fact that the addressee agrees with the compliment assertion to some extent; henceforth, the type of the compliment response referred to as scaled-down agreement. The last two components have to do with the generalization that compliment interaction routines are characterized by a hail of uncertainty in Iran.

In order to contrast the Persian pattern with that of English, the following extract will be in order:

Extract 8 (English):

A: I think your book is very useful.

B: Yes, It really is.

The speaker involved in this conversation is offering praise for the addressee's book. Yet, the addressee agrees with the speaker, expressing agreement over the quality of the book. The following cultural scripts can be suggested for this communicative interaction:

\section{A: (a) I think something about you is good.}

B: (b) I think the same

(c) I think it is good I don't want to say: very good 
Components (a) and (b) and (c) are similar in both English and Persian. Note that these components have been fully described before.

\subsection{Reassignment of Praise}

A common type of compliment response that occurs in English and Persian is referred to as reassignment of praise. Pomerantz (1978) defines it as an entity in which the addressee agrees with the compliment assertion, but the compliment is shifted to some third person or object. Yet in Persian once the compliment is addressed to a Persian speaker, he usually disagrees with the compliment assertion to avoid self-praise. The following example illustrates the point.

Extract 9 (Persian):

A: Cheghadr ghashang sohbat mikonid!

[how much beautiful talk you do.]

'How beautifully you talk!'

B: Khaahesh mikonam. Age chizi ham hast vaghean be khaatere falsafe ast.

[welcome do-I. if something too is really to reason philosophy is.]

'You are welcome. If I do, it is really due to philosophy.'

The exchange unit is from a situation in which a philosopher is being praised by two TV interviewers. However, the philosopher reassigns the praise and shifts the credit from himself to something else (philosophy).

This example suggests the following cultural scripts:

A: (a) I think something about you is very good

B: (b) I think the same

(c)I would say $\mathrm{X}$ is very good

C: ( d) I don't think the same

(e) I would want to say something other than this

(f) I would want to say something other than me is good

In contrast, the following English example depicts a situation in which the speaker shifts the praise from the person himself to some good quality of the person addressed.

Extract 10 (English):

A: Biff is quarterback in his team.

B: Well, that is nice, isn't it?

A: Good health

This communicative interaction routine can be portrayed within the following cultural scripts:

A: (a) I think that something about you is very good

B: (b) I would want to say something other than this

I would say that something about something other than this is good

Component (a) in both English and Persian postulates that the speaker is asserting praise to the addressee, the meaning implicit in all compliment routines. Component (b) in Persian shows that the second speaker agrees on what is being said. While self praise is not desirable in Iranian culture, praising others is highly valued. Component (d) spells out that the addressee does not agree with the speaker on the compliment assertion to avoid self-praise. Component (e) postulates that the speaker is shifting the credit to something other than himself, hence, reassignment of praise the type of compliment response used. The English prescription comprises of two components: (a) gives the idea that some good characteristic of the addressee is the target of the compliment and, (b) shows the type of the compliment response used.

It should be noted that reassignment of praise ought to be interpreted with a careful consideration of the situation in which it occurs. For example, in Persian interaction routines one may often hear others talk highly of one's achievements in one's studies, business, and other daily activities. The addressee normally does not accept the praise, shifting the credit to the favors of the whole. The following extract, taken form a program reviewing the achievements of some Iranian champions, will clarify the point. 
Extract 11 (Persian):

A: Az in ke in maghaam ro dar sathe jahaan be dast aavardid, vaghean behetoon tabrik migam.

[from this that this position-obj-marker in scope world gain you did really to you congratulation say I do.]

'I really congratulate you on gaining such a position in the world.'

B: Man in moffaghiat ro madyuneh doaye mardome azizemun hastam and...

[I this achievement-obj.marker owe prayer-of nation dear am and...]

'I owe this achievement to prayers of our dear nation and...'

The interviewer congratulated Hossein Rezazadeh, the Iranian Olympic weightlifter champion, who won the gold medal in the Olympic Games of 2000 and 2004. He, however, professed that he obtained such great achievements owing to the goodness, favors, and prayers of the whole nation. This cultural norm can be represented as follows:

A: (a) I think you did something very good

B: (b) I wouldn't say this

(c) I would say I am not good

(d) I can't do things well

\section{Conclusions and implications}

The present paper supports Wierzbicka's (1991) idea that the communicative interaction routines are realized with regard to different cultural norms in different communities. Indeed, speakers of a given culture have been shown to have mutually shared expectations about what the appropriate behavior and its social meanings are in different contexts (Blum-Kulka 1987). For compliment responses, the practice in American culture, which places special emphasis on agreement in discoursal activities, appears to be for the speaker to respond to compliments with acceptance forms. By contrast, the practice in Persian society, which attaches a high value to relative power and modesty in spoken interactions, seems to be that the speaker will respond to compliments with non-acceptance forms. In addition, we can now see how cultural norms and social factors may intervene in determining the distinctive patterns of compliment response behavior for a given speech community. It thus goes without saying that the important role socio-cultural norms play should never be treated lightly when exploring the cross-cultural evidence for evaluating the universality of speech act performance.

As it was shown, the cultural scripts described the characteristics of English and Persian use of compliments and the underlying cultural values accurately. This level of accuracy could not have been achieved by reliance on some abstract concepts or Western models of politeness driven by an Anglocentric perspective such as Brown and Levinsons` Politeness Model. In all cases scripts and explications were presented in parallel, precisely equivalent versions, using the natural semantic metalanguage expressed via English and Persian. This served to demonstrate both that the metalanguage itself is not tied to any single language, either to English or to Persian, and that the cultural scripts method provides a vehicle whereby cultural outsiders can access and understand Persian compliments much better.

In the last few years, however, another direction of studies has focused on the effects of explicit teaching of L2 pragmatics and intercultural communication and the development of pragmatics in L2 learners (Kasper, 2001). These studies on L2 pragmatic instruction have examined the effect of implicit versus explicit teaching approaches on specific aspects of L2 pragmatics and suggest that explicit instruction may be effective for developing socio-pragmatic proficiency.

The present paper paves the way for a novel approach for explicitly teaching L2 socio-pragmatics in general and compliments in particular to EFL learners by providing them with authentic exemplars from L2 social interactions that are based on findings in conversation analysis (CA) and presented through cultural scripts. These materials also provide translation students and translators not only with explicit information about socio-pragmatic norms, but also with opportunities to practice and use the learned L2 socio-pragmatic norms as they translate from one language into another and vice versa.

As mentioned before, studies with respect to the use of the semantic metalanguage to describe language are still at an early stage of development. In order to broaden horizons in teaching cultures with an appeal to the use of the semantic metalanguage, further studies are required. Nonetheless, the authors think that there is the possibility of using the semantic metalanguage in teaching L2 socio-pragmatics (e.g., compliments) and translation. The scripts proposed to describe an interactional meaning can be employed to bring about awareness within the learners of the form, illocutionary purpose, and the cultural norms implicit behind it. Besides, the use of the scripts makes it 
possible to compare and contrast different ways of interaction in different cultures. According to Wierzbicka (1991, 2004, 2007), semantics can be regarded as a key to cross-cultural differences. Therefore, semantics presented in terms of cultural scripts can be used to teach the pragmatic aspect of language.

In spite of the fact that cultural scripts can be used in teaching L2 socio-pragmatics, they should be applied to teaching adult learners rather than children on the ground that the syntactic patterns and the lexicon used in the formation of the scripts are, to some extent, complex, and that they deal with the meaning implicit in communicative interaction routines. Furthermore, in order to see whether or not they produce effective results, they must be empirically tested.

\section{Suggestions for further research}

The application of the semantic metalanguage to describe communicative interaction routines can be said to be still intact. However, it is for the interested readers to decide to undertake further research in the area of L2 socio-pragmatics. The following suggestions can be used as departures for further studies in the area:

-Directness versus indirectness (including imperative and whimperative constructions), and requestive behavior involving rejection of requests and offers can be explained and taught using the cultural script model.

-People living in a foreign community are brought up with a certain set of values and ways of life that constitute an entity called "culture". Portion of these values and ways of life are realized in communicative interaction routines. Sayings, proverbs, and percepts are used to convey special meanings. Persian is rich in the use of sayings, proverbs, and percepts. These aspects of the Persian language, regarded a direct reflection of cultural values, can be described within the framework of the semantic metalanguage presented in cultural scripts.

-By taking a linguistic perspective- examining conventional linguistic descriptions of facial expressions in Persian and studying their meanings with a culture-independent semantic theory of Natural Semantic Metalanguage (NSM) - one may reveal a culture-internal understanding of facial expressions and their relationship to emotions, thus providing much needed information on how people from a non-Anglo culture conceptualize facial expressions and emotions. The paraphrase approach of NSM avoids attributing an emotion term to an expression that includes no explicit reference to an emotion.

- As Wierzbicka has tried to show in her book English: Meaning and Culture (Wierzbicka, 2006), English itself is not culturally and ideologically neutral: on the contrary, it is steeped in culture - Anglo culture. When the Iranian tries to engage in dialogue, they need, first of all, to try to explain their own position. To do this effectively, they may need to strip themselves of the complex language to which they are accustomed and which they normally take for granted. The closer the explanations get to the level of simple and universal human concepts the more comprehensible they will be to outsiders. If we as members of a particular group (cultural, religious, or any other) try to speak to others using our own terminology and our own complex but familiar constructs we will be talking to ourselves. To promote dialogue we will do well to promote the use of simple and universal human concepts. Dialogue can facilitate such understanding, and shared human concepts can facilitate dialogue, and communication of any kind. For someone interested in dialogue the Natural Semantic Metalanguage, based on shared human concepts, will be a valuable practical tool.

\section{References}

Barnlund, D. C. \& Akari. S. (1985). Intercultural encounters: the management of compliments by Japanese and Americans. Journal of Cross-Cultural Psychology, 16, 9-26.

Beeman, W. O. (1986). Language, Status and Power in Iran. Indiana University Press.

Blum-Kulka, S. (1987). Indirectness and politeness in requests: same or different? Journal of Pragmatics, 1, 31-146.

D'Andrade, Roy. (2001). A cognitivist's view of the units debate in cultural anthropology. Cross-Cultural Research, 35(2), 242-257.

Goddard, C. \&Wierzbicka. A. (1994). Semantic and Lexical Universals: Theory and Empirical Findings. Amsterdam: John Benjamins.

Goddard, C. \& Wierzbicka. A. (2004). Cultural scripts: What are they and what are they good for? Intercultural Pragmatic,s 32, 153-166.

Golato, A. (2002). German compliment responses. Journal of Pragmatics 34, 547-571.

Golato, A. (2003). Studying compliment responses: A comparison of DCTs and recordings of naturally occurring talk. Applied Linguistics, 24, 90 - 121. 
Herbert, R. K. \& Straight. S. (1989). Compliment-rejection versus compliment- avoidance: listener-based versus speaker-based pragmatic strategies. Language and Communication, 9, 35-47.

Holmes, J. \& Brown. D. F. (1987). Teachers and students learning about Compliments. TESOL Quarterly, 21, $523-546$.

Kasper, G. (2001). Linguistic politeness: current research issues. Journal of Pragmatics, 14, 93-218.

Knapp, M., R. Hopper and R. A. Bell. (1984). Compliments: a descriptive taxonomy. Journal of Communication, 34, 12-31.

Pomerantz, A. (1978). Compliment responses: notes on the cooperation of multiple Constraints. In J. Schenkein (ed.) Studies in the Organization of Conversational Interaction. Academic Press, New York, NY, pp. $79-112$.

Saito, H. \& Masako. B. (1997). An approach to instruction of pragmatic aspects:implications of pragmatic transfer by American learners of Japanese. Modern Language Journal, 81, 363-377.

Sharifian, F. (2005). The Persian cultural schema of shekaste-nafsi: A study of compliment responses in Persian and Anglo- Australian speakers. Pragmatics and Cognition, 13(2), 337-361.

Taleghani-Nikazm, C. (2002). A conversation analytical study of telephone conversation openings between native and nonnative speakers. Journal of Pragmatics, 34(12), 1807-1832.

Tang, C. \& Zhang. G. (2009). A contrastive study of compliment responses among Australian English and Mandarin Chinese speakers. Journal of Pragmatics, 4, 325- 345.

Wieland, M.(1995). Complimenting behavior in French/American cross-cultural dinner Conversations. The French Review, 68, 796-812.

Wierzbicka, A.(1991). Cross-cultural pragmatics: the semantics of human interaction. Berlin: Mouton de Gruyter.

(1994). Cultural scripts: A semantic approach to cultural analysis and cross-cultural communication. In Lawrence B. and Y. Kachru (ed.) Pragmatics and Language Learning, Urbana-Champaign: University of Illinois.

(10), 575-599.

(2004). Jewish cultural scripts and the interpretation of the Bible. Journal of pragmatics, 36

(2006). English: Meaning and culture. New York: Oxford University Press.

. (2007). Bodies and their parts: An NSM approach to semantic typology. Language Sciences, 29,

$14-65$.

Wolfson, N. \& Manes. J. (1980). The compliment as a social strategy. Papers in Linguistics, 13, 391-410.

Notes

Note1: In transcriptions from Persian, the letter "a" symbolizes a low front vowel which is close to the sound of "a" in the word "cat". The "aa" sequence, on the other hand, stands for a low back vowel which is close to the sound of "a" in the word "father". 